\title{
EFFECT OF WEATHER TEMPERATURE ON FIRST IMPRESSION ABOUT ANOTHER PERSON
}

\author{
Martirosyan D. M. (École Polytechnique Fédérale de Lausanne, \\ Lausanne, Switzerland) \\ davit.martirosyan@epfl.ch

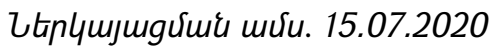

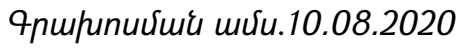

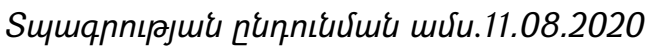

This research study investigates the hypothesis that warmer external temperature leads to a more positive first impression of one's emotion and personality. The study involved two groups of participants, one for each weather setting (cold and warm outside temperature). The participants were asked to fill in a google form questionnaire consisting of a consent form, basic information about their gender, age and nationality, POMS-A test to evaluate their mood at the time, personality and emotion assessment of two pictures (male and female), and a question about their weather preference. Four MANOVA models were constructed: one to test differences among emotions, and another - among personality traits for each picture. All models produced insignificant results ( $p$ value $>0.05$ ), thus giving us insufficient evidence to reject the null hypothesis of external temperature having no effect on the formation of first impressions. After presenting the findings, potential reasons for obtaining such results are discussed.

Keywords: emotions, perception, mood, warm-cold temperatures, personality.

Introduction. We quickly form a certain impression of one's character upon meeting and we hardly ever think about what made us form the first impression that we did. Psychology has been interested in finding the basis of interpersonal liking for many years. It all began with Solomon Asch's original experiment [1] where he demonstrated how 'warm' and 'cold' adjectives describing personality traits affected the first impressions we form of other people. In addition to interpersonal warmth or trust, physical warmth has emerged as a potential key factor in social judgment [2]. Subsequently, the impacts of ambient temperature on social proximity [3] and prosocial behavior [4] have been studied in recent years. Nevertheless, how external temperature (e.g. weather outside) affects our judgment of other people is still to be addressed. Therefore, this study aims to fill in this research gap, and provide a better understanding of the effects of weather temperature on first impression interpersonal judgement. 
The concept of psychological warmth has been the subject of many research articles. As mentioned previously, Solomon Asch's pioneering work about first impressions inspired upcoming studies on social perception and interpersonal liking. Belkin and Kouchaki [4] studied the connection between ambient temperature and individual prosocial behavior. They found that in hot temperatures, in contrast to normal, people were less likely to display prosocial behavior. Williams and Bargh's study [2], which focused on how experiencing physical warmth impacted interpersonal warmth, found out that holding a warm cup of coffee made people have more positive first impressions as opposed to holding a cold cup of coffee.

A little deviation from these two studies is the discussion by IJzerman et al. [5]. The authors explored how social exclusion led to lower skin temperature. They found that being excluded from a group decreased the temperature in person's fingertips.

The studies about interpersonal distances are particularly interesting. Interpersonal distance can be defined as the smallest distance that one feels comfortable with when in proximity with another person. IJzerman and Sermin [3] showed that the participants who were handed a warm beverage scored higher on the perceived degree of overlap between self and other, i.e. warmer conditions induced more social proximity than cold conditions. A research paper by Ruggiero et al. [6] focused on studying the difference in preferences of interpersonal distance depending on gender. Although both genders appreciated the warm drink more, men preferred larger interpersonal distances when holding a warm cup $\left(57^{\circ} \mathrm{C}\right)$, while women preferred larger interpersonal distances when holding a cold cup $\left(10^{\circ} \mathrm{C}\right)$.

In extending this line of research, the current study investigates how weather temperature might impact the participants' judgment of others. Specifically, the effects of cold/warm weather temperature on forming a first impression about personality and emotions of other individuals are measured. Based on the research studies conducted previously, it was hypothesized that warmer (colder) external temperature would lead to a more positive (negative) judgment of one's personality and emotions.

Method

Participants: It was initially planned to carry out the experiment in two phases survey a group of people in cold weather (early spring), then survey another group of people in late spring, in warmer weather. However, because of the restrictions created by the global pandemic of COVID-19, there was only time to survey people in cold weather (before mid-March 2020). The data collection for the warm weather group was done completely remotely using google forms, i.e. participants were emailed surveys to complete at their homes.

111 people took part in the experiment, 42 of them were surveyed outside the Rolex center of EPFL in cold weather, while 69 (64 + 5 follow-ups from cold setting) people were contacted and surveyed remotely to make up the warm weather group. 
There were participants from 26 different countries. The average ages of the participants were 24.19 (with std of 8.21) and 23.91 (with std of 6.84) in cold and warm weather setting respectively. In other words, the age distribution was quite similar in both weather conditions.

Materials

Pictures: Two photos (one of male and one of female, see on the right) were selected from a set of 4900 pictures of human facial expressions of emotions developed at Karolinska Institutet, Department of Clinical Neuroscience, Section of Psychology in Stockholm, Sweden.

Understanding that some bias could be introduced with the
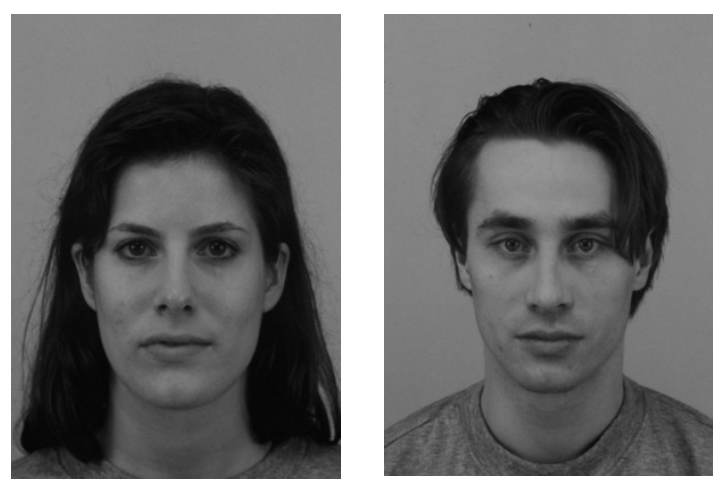
pictures chosen, an extra care was applied to select pictures that display neutral faces. Additionally, having pictures of both genders would allow to test whether there was any difference in how people assessed different genders.

Mood assessment test: With the assumption that mood influences people's judgement of others [7], the participants' mood at the time of the experiment was recorded. The mood was measured with POMS-A (24-item questionnaire), which is a shorter version of POMS (Profile of Mood States: 65-item questionnaire) test [8]. POMS-A was developed by Terry et al. [9] specifically for the use with adolescents and children, however it was later verified that its results were still reliable when used with adults [10]. The test assesses mood along 6 dimensions - anger, confusion, depression, fatigue, tension, and vigor (the only positive dimension). Each dimension consists of 4 mood states. The words were presented to participants in a dimensioninconsistent order. They were then asked to rate to what extent each word described how they felt at that time on a 0 to 4 scale.

The mood disturbance score was calculated by subtracting the sum of all negative mood states (20 items) from the sum of scores for lively, energetic, active and alert that make up vigor. Note that the more negative (positive) the score is the worse (better) that person's mood.

Emotion assessment test: The emotion assessment test from the study by Bouhuys et al. [11] was used, which includes the following 6 emotions: happiness, sadness, anger, fear, surprise, and disgust. For each of the 6 emotions, a participant could choose from 'none' to 'very so' on a discrete $0-4$ scale ( 0 and 4 corresponding to 'none' and 'very so' respectively) to describe the person's face in each photo. This is one of the dependent variables of this study. 
Personality assessment test: Participants were asked to choose one word from each pair of opposing characteristics (see below) that best described the person appearing in the photo.

Generous - Ungenerous; Wise - Unwise; Good-natured - Irritable; Humorous Humorless;

Sociable - Unsociable; Humane - Ruthless; Caring - Selfish; Imaginative Hard-headed.

This list of pairs is a modified version of the original list created by Solomon Asch [1]. Firstly, only the pairs were kept that showed significant differences between the "warm" and "cold" group responses (10 in total). Secondly, since happiness would be recorded in the emotion assessment test, the unhappy-happy pair was removed. The popular-unpopular pair was also discarded because it is not exactly a personality trait. Lastly, altruistic-self-centered was replaced with caring-selfish, and wise-shrewd with wise-unwise for added clarity. Finally, we were left with the list of 8 pairs of opposing personality traits.

Each pair was modelled as a categorical variable with 2 levels - 0 and 1 corresponding to the negative and positive trait respectively in each pair. Personality trait is a dependent variable in this study.

Procedure. Since two significantly different weather temperatures were needed, the experiment was done in two phases: the cold weather group was surveyed in the beginning of March 2020 (around $8^{\circ} \mathrm{C}$ ) and the warm weather group participated remotely. Since the temperature of the participants' home environment was most likely much warmer than $8^{\circ} \mathrm{C}$, it was decided that asking people to fill in the survey at their homes was an appropriate way to collect data for the warm weather condition given the circumstances. For the first phase, students outside the EPFL campus library were asked at random if they would take part in the experiment. Those who agreed were then asked to fill in the google form questionnaire. For the second phase, EPFL students and other people with similar background were targeted to fill in the form remotely.

The first sections of the questionnaire consisted of the consent form, basic information about their gender, age and nationality. After finishing these sections, the participants completed the POMS-A test which was used to assign a score to their mood. Emotion and personality assessments of the two pictures were next.

The emotion assessment consisted of rating how much each of the following emotions was present in the given picture: happiness, sadness, anger, fear, surprise, and disgust. Whereas the personality assessment was done by choosing one word from each pair in the list of characteristics that best described the person appearing in the picture.

At the end of the questionnaire, participants were asked about their preferred outside temperature (warm, cold, no preference). The question about their weather 
preference was masked among 3 other random questions. The reason behind this was to avoid the participants guessing the intent behind knowing what weather temperature they preferred.

Statistical analysis. Power analysis, done with the G-power software, showed that 122 (61 for each weather setting) participants were needed for an effect size of 0.2 , an error probability of 0.05 and a power of 0.95 . In fact, only 112 participants were needed for testing the difference among 6 emotion scores, but 122 participants were required for testing the difference among 8 personality traits. Due to the large impact of COVID-19 on everyday normalcy there was not enough time to collect as many data points for the cold weather group (42 were collected out of 61 planned).

After collection, the data was then prepared for analysis. Since the number of follow up participants was low (5 in total), it was decided not to carry a within-subject analysis. Consequently, these participants were excluded from the warm weather group to remove possible bias that would be introduced due to those people being exposed to the questions once before. It was also found that the personality assessment test was partially incomplete for some participants. For the male picture, there were 7 such cases ( 3 in cold and 4 in warm weather setting), and for the female picture -3 cases ( 2 in cold and 1 in warm weather setting). These missing values were removed bringing the number of participants down to 99 and 103 out of the original 106 for the male and female picture respectively. These data points were used when modelling the personality characteristics as the dependent variable.

The dependent variables of this experiment are perceived personality traits and emotions. Various factors were measured that could act as covariates such as age, mood, gender of participants and their weather preferences.

Multivariate analysis of variance (MANOVA) was performed to test the hypothesis. This method was justified since both dependent variables had multiple dimensions ( 6 in case of emotions and 8 in case of personality). 2 different MANOVA models were constructed in SPSS for each of the two photos - the first model tested the differences between each of the 6 emotion scores in cold and warm weather setting, and the second model tested the differences between each of the 8 personality pairs in cold and warm weather setting. In each model, weather setting (cold or warm) was used as a fixed factor. Neither of age, overall mood score, gender of participants and their weather preferences was included as a covariate due to little correlation $(<0.3$ [12], see Table 1$)$ with the dependent variables. 
Table 1. Max absolute correlations of controlled variables with dependent variables in each model.

\begin{tabular}{|l|c|c|c|c|}
\hline $\begin{array}{l}\text { Model } \backslash \text { Controlled } \\
\text { Variables }\end{array}$ & Age & $\begin{array}{c}\text { Mood } \\
\text { score }\end{array}$ & $\begin{array}{c}\text { Gender (of } \\
\text { participants) }\end{array}$ & $\begin{array}{c}\text { Weather } \\
\text { preference }\end{array}$ \\
\hline $\begin{array}{l}\text { Model 1: (male pic, } \\
\text { emotions) }\end{array}$ & 0.12 & 0.21 & 0.07 & 0.07 \\
\hline $\begin{array}{l}\text { Model 2: (male pic, } \\
\text { personality traits) }\end{array}$ & 0.20 & 0.20 & 0.22 & 0.10 \\
\hline $\begin{array}{l}\text { Model 3: (female pic, } \\
\text { emotions) }\end{array}$ & 0.17 & 0.25 & 0.15 & 0.12 \\
\hline $\begin{array}{l}\text { Model 4: (female pic, } \\
\text { personality traits) }\end{array}$ & 0.21 & 0.25 & 0.24 & 0.20 \\
\hline
\end{tabular}

MANOVA assumes that the vector of the dependent variables follows a multivariate normal distribution, and the variance-covariance matrices of the dependent measures of each group are equal. Since both groups (cold and warm) had sufficiently large (>30) number of data points, the first assumption was considered satisfied by Central Limit Theorem. However, as an additional check kurtosis and skewness values of the dependent variables were investigated. Although few of the kurtosis values were not in the recommended range of $[-2,+2]$ suggested by George and Mallery [15] and Khan [16], the deviations were small and therefore not crucial for MANOVA to work [14].

To test the second assumption, Box's $M$ test of equality of covariance matrices was calculated (see Table 2). Significance values greater than 0.05 were obtained for all the models suggesting that the second assumption was also met.

Table 2: Box's M p-values for each model.

\begin{tabular}{|l|c|c|c|c|}
\hline & $\begin{array}{c}\text { Model 1: } \\
\text { (male pic, } \\
\text { emotions) }\end{array}$ & $\begin{array}{c}\text { Model 2: } \\
\text { (male pic, } \\
\text { personality } \\
\text { traits) }\end{array}$ & $\begin{array}{c}\text { Model 3: } \\
\text { (female pic, } \\
\text { emotions) }\end{array}$ & $\begin{array}{c}\text { Model 4: } \\
\text { (female pic, } \\
\text { personality } \\
\text { traits) }\end{array}$ \\
\hline Box's M sig. & 0.775 & 0.392 & 0.814 & 0.614 \\
\hline
\end{tabular}

Results.

Cronbach's measure of internal consistency (alpha) [18] for POMS-A was 0.872 (reliability coefficient of 0.7 and higher is considered good [17]) suggesting that the scale was reliable, and POMS-A results were valid. Table 3 reports the average inter- 
item correlations (sum of pairwise correlations over the number of variables) for each model. The average inter-item correlation for each model was within the recommended range of $[0.15,0.50]$ suggested by Briggs and Cheek [13], hence the items of each dependent variable were well correlated and were measuring the same idea making the participants' reported scores reliable.

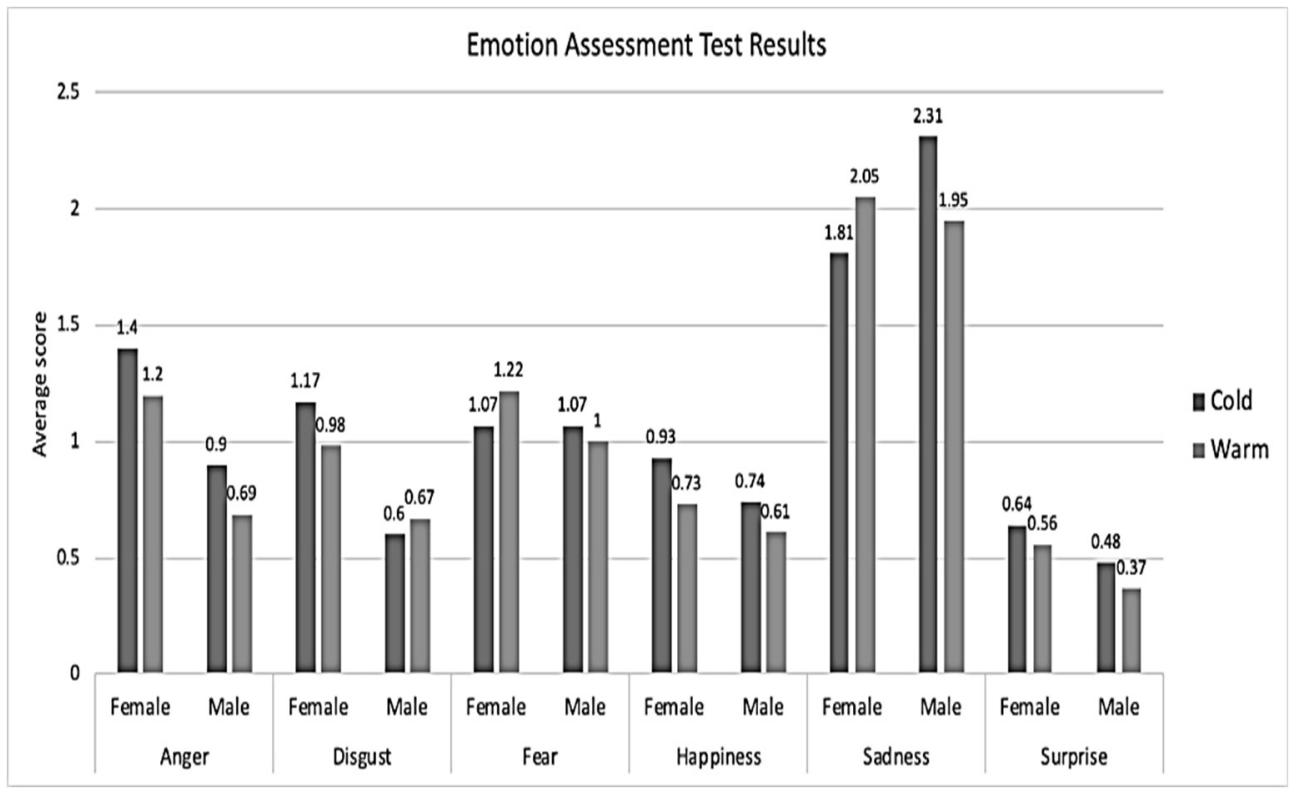

Figure 1: Distribution of average emotion scores for each model in each weather group - gender refers to pictures not participants.

Figure 1 shows the distribution of average emotion scores for each picture in each weather setting. For both pictures, the observed scores differed only slightly between the two weather settings. However, when fixing the weather and comparing the scores of each emotion for male and female pictures, some differences became apparent. Indeed, t-test revealed that the differences in anger (both weather settings) and in disgust (cold setting) between male and female pictures were significant ( $p$ values of 0.026 and 0.005 for anger in cold and warm settings respectively, and $p$ value of 0.009 for disgust).

Table 3: Average inter-item correlations.

\begin{tabular}{|l|c|c|}
\hline Picture gender \Item & Emotions & Personality traits \\
\hline Male picture & 0.16 & 0.15 \\
\hline Female picture & 0.19 & 0.22 \\
\hline
\end{tabular}


Figure 2 shows the proportions of the participants selecting the positive trait from each pair of personal characteristics for each picture in each weather setting. For both pictures, the distributions of proportions for each weather setting were quite similar. Nevertheless, when fixing the weather and comparing the scores of each personality pair for male and female pictures, some differences emerged. Indeed, ttest revealed a significant difference between the imaginative-hard-headed pair for male and female picture in both weather settings. The $p$-values were 0.031 and 0.000 for cold and warm setting respectively.

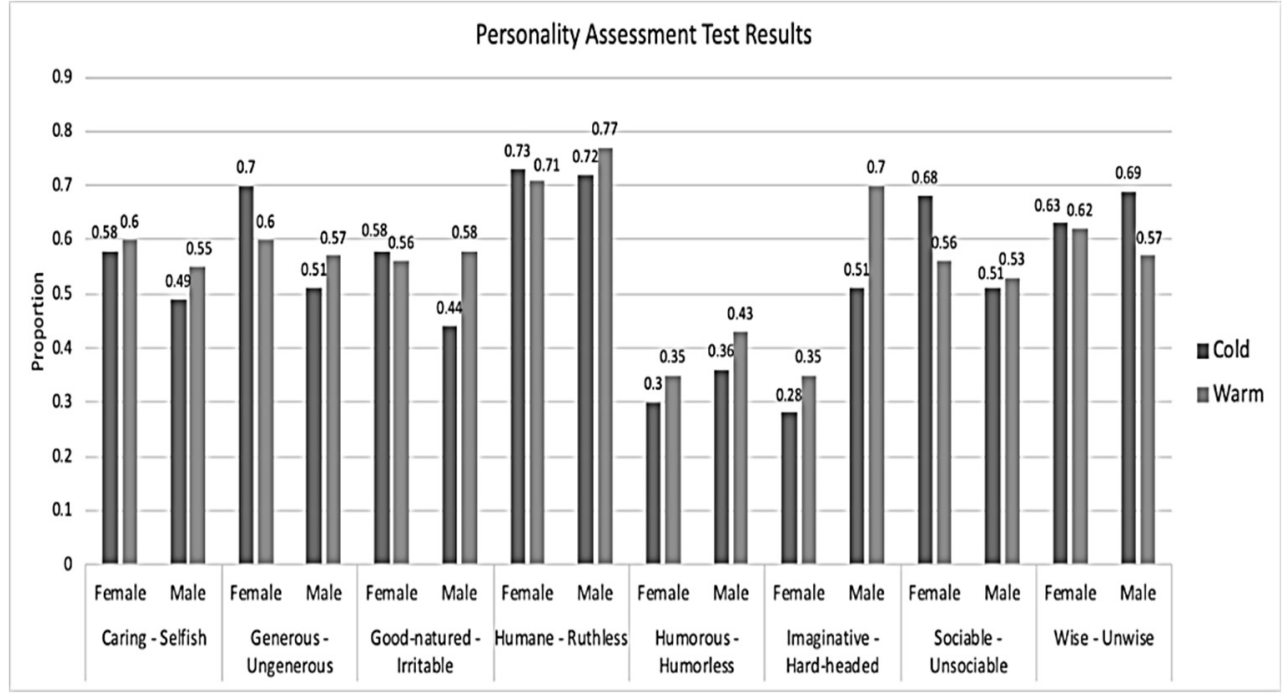

Figure 2: Proportion of participants who selected the positive trait (e.g. caring, generous, etc.) for each model in each weather group - gender refers to pictures not participants.

Moving forward, Table 4 summarizes the average mood scores of the participants grouped by gender in each weather setting. Interestingly, there was a significant difference in the average mood scores of male and female participants in cold weather (-3.65 vs -13.79$)$. In addition, the average mood score of the female participants was more negative across both weather settings. Furthermore, the male participants recorded a big drop in their average negative mood score while females showed slightly increased average negative mood score.

Table 4: Average mood scores.

\begin{tabular}{|c|l|l|}
\hline Participant gender $\backslash$ Setting & Cold weather & Warm weather \\
\hline Male & -3.65 & -9.08 \\
\hline Female & -13.79 & -12.89 \\
\hline
\end{tabular}


Finally, the test results of Pillai's Trace and Wilk's Lambda of the 4 MANOVA models are summarized in Table 5 . As shown in the table, the calculated F-statistics and $p$-values for all models were the same for both tests. The p-values indicated insignificant results at a significance level of 0.05 . Hence, there was not enough evidence to reject the null hypothesis of weather temperature having no effect on judgment of one's personality and emotions. This result was expected after discussing Figures 1 and 2, where very little difference in the distributions of each dependent variable in cold and warm weather settings were observed.

Table 5: MANOVA results for each model.

\begin{tabular}{|l|c|c|c|c|}
\hline Model $\backslash$ Results & $\begin{array}{c}\text { Pillai's } \\
\text { Trace: } \\
\text { p-value }\end{array}$ & $\begin{array}{c}\text { Pillai's } \\
\text { Trace: } \\
\text { F-statistic }\end{array}$ & $\begin{array}{c}\text { Wilk's } \\
\text { Lambda: } \\
\text { p-value }\end{array}$ & Wilk's Lambda: \\
F-statistic \\
\hline $\begin{array}{l}\text { Model 1: (male pic, } \\
\text { emotions) }\end{array}$ & 0.249 & 1.335 & 0.249 & 1.335 \\
\hline $\begin{array}{l}\text { Model 2: (male pic, } \\
\text { personality traits) }\end{array}$ & 0.586 & 0.821 & 0.586 & 0.821 \\
\hline $\begin{array}{l}\text { Model 3: (female pic, } \\
\text { emotions) }\end{array}$ & 0.664 & 0.682 & 0.664 & 0.682 \\
\hline $\begin{array}{l}\text { Model 4: (female pic, } \\
\text { personality traits) }\end{array}$ & 0.759 & 0.621 & 0.759 & 0.621 \\
\hline
\end{tabular}

Discussion: This section outlines possible reasons for achieving non-significant results. First and possibly the most apparent reason is the difference in data collection for each weather setting. For the cold weather group, participants were approached and surveyed outside, and so a lot of human interaction was involved in the process. In contrary, the data collection for the warm weather group was done completely remotely. Additionally, the warm weather group completed the survey at their homes, and there would have been natural variations in temperature from one person's home to another's. The change in data collection process was due to unforeseen circumstances (COVID-19), and in hindsight, these changes could have had unwanted effects on the results.

Another reason is the small dataset - 42 out of planned 61 participants were recruited which reduced the hypothetical statistical power of 0.95 for the experiment. If this experiment were to be repeated, a bigger number of data points could potentially improve the statistical power of the analysis.

Although there was not enough evidence to support the hypothesis, valid and reliable data was collected. In addition, the ideas presented and discussed in this research paper can serve as building blocks to conduct experiments in this area with the suggested improvements outlined in this section. 
Acknowledgement: I sincerely thank Prof. Ahmad Abu-Akel for providing guidance and feedback throughout the project. Thanks also to Maria-Smaranda Pandele and Ariane Andrée Marie Delrocq for helping me in experimental design and data collection.

\section{References}

1. Asch, S. E. (1946). Forming impressions of personality. The Journal of Abnormal and Social Psychology, 41 (3),pp. 258-290.

2. Williams, L. E., \& Bargh, J. A. (2008). Experiencing physical warmth promotes interpersonal warmth. Science, 322 (5901), pp.606-607.

3. IJzerman, H., \& Semin, G. R. (2009). The thermometer of social relations: Mapping social proximity on temperature. Psychological Science, 20, pp. 12141220.

4. Belkin, Y. L., \& Kouchaki M. (2017). Too hot to help! Exploring the impact of ambient temperature on helping. European Journal of Social Psychology, 47, pp. 525-53.

5. IJzerman, H., Gallucci, M., Pouw, W. T.J.L., Weibgerber, S. C., Van Doesum, N. J., \& Williams, K. D. (2012). Cold-blooded loneliness: Social exclusion leads to lower skin temperatures. Acta Psychologica, 140, pp.283-288.

6. Ruggiero, G., Rapuano, M., \& lachini, T. (2019). Perceived temperature modulates peripersonal and interpersonal spaces differently in men and women. Journal of Environmental Psychology, p. 63, pp. 52-59.

7. Forgas, J. P., \& Bower, G. H. (1987). Mood Effects on Person-Perception Judgments. Journal of personality and social psychology, p.53, pp. 53-60.

8. McNair, D. M., Lorr, M., \& Droppleman, L. F. (1971). Manual for the Profile of Mood States. San Diego, CA: Educational and Industrial Testing Services.

9. Terry, P. C., Lane, A. M., Lane, H. J., \& Keohane, L. (1999). Development and Validation of a Mood Measure for Adolescents. Journal of sports sciences, p. 17, pp. 861-72.

10. Terry, P. C., Lane, A. M., \& Fogarty, G. J. (2003). Construct validity of the Profile of Mood States - Adolescents for use with adults. Psychology of Sport and Exercise, 4, pp. 125-139.

11. Bouhuys, A. L., Bloem, G. M., \& Groothuis, T. G.G. (1994). Induction of depressed and related mood by music influences the perception of facial emotional expressions in healthy subjects. Journal of Affective Disorders, p.33, pp. 215-226.

12. Dancey C.P., Reidy J. Pearson Education; 2007. Statistics without Maths for Psychology.

13. Briggs, S.R., Cheek, J.M., 1986. The role of factor analysis in the development and evaluation of personality scales. Journal of Personality.p. 54, pp. 106-148. 
14. Schmider, E. \& Ziegler, Matthias \& Danay, Erik \& Beyer, Luzi \& Buhner, M.. (2010). Is it really robust? Reinvestigating the robustness of ANOVA against the normal distribution assumption. Meth Eur J Res Meth Behav Soc Sci. p.6. pp.15-147.

15. George, D., \& Mallery, M. (2010). SPSS for Windows Step by Step: A Simple Guide and Reference, 17.0 update (10a ed.) Boston: Pearson.

16. Khan, A. F. (2015). Assessment of Midlife career Stress on Indian Managers. Ph.D Thesis. Aligarh Muslim University.

17. Tabachnick, B.G., \& Fidell, L.S. (1996). Using Multivariate Statistics. New York, NY: Harper and Row.

18. Cronbach, L.J. (1951). Coefficient alpha and internal structure of tests. Psychometrika, p. 16, pp. 297-334.

\section{ВЛИЯНИЕ НАРУЖНОЙ ТЕМПЕРАТУРЫ НА ПЕРВОЕ ВПЕТЧАТЛЕНИЕ О ЧЕЛОВЕКЕ}

Мартиросян Д. М. (Федеральная политехническая школа

Лозанны, Лозанна, Швейцария)

В данном исследовании рассматривается гипотеза о том, что более теплая наружная температура ведет к более позитивному первому впечатлению к личности" В исследовании участвовали две группы участников, по одной для каждой погодной обстановки (холодная и теплая наружная температура). Участников исследования просили заполнить google форму, состоящую из фрормы согласия, основной информации об их гендере, возрасте и национальности, пройти тест POMS-А для оценки их текущего настроения, ответить на вопросы об их погодных предпочтениях, а также о личностной и эмоциональной оценке двух изображений (мужчины и женщины). Были применены четыре модели для многомерного дисперсионного анализа (MANOVA): по одной для оценки разницы при разных эмоциях и при разных личностных чертах для каждого изображения. Все модели дали статистически незначимые результаты (р-критерий> 0.05), что не дало достаточных оснований для отвержения нулевой гипотезы, говорящей об отсутствии влияния наружной температуры на формирование первого впечатления. Помимо представления самих результатов, также обсуждаются их потенциальные причины.

Ключевые слова: эмоции, восприятие, настроение, теплая-холодная температура, личность. 


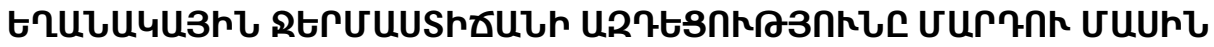

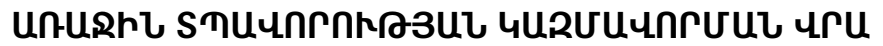

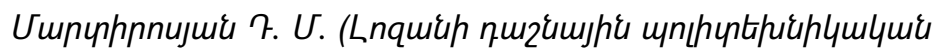

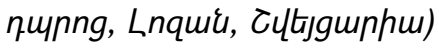

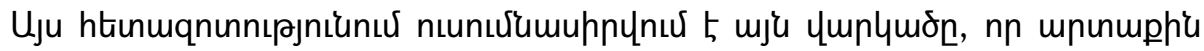

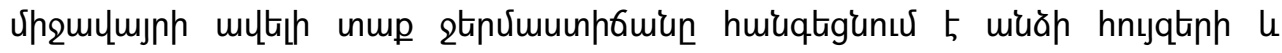

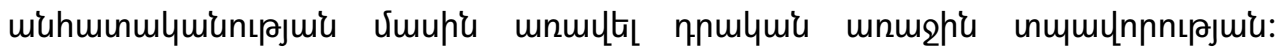

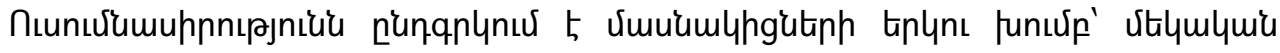

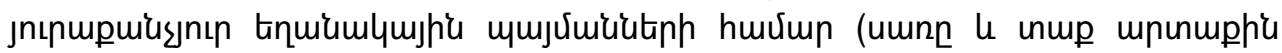

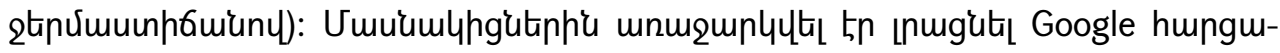

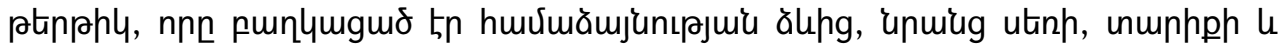

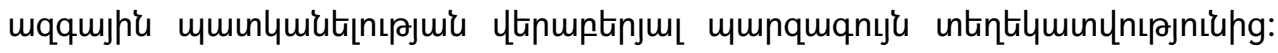

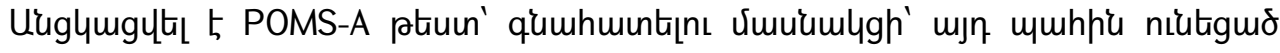

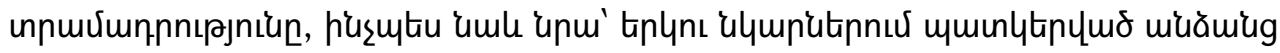

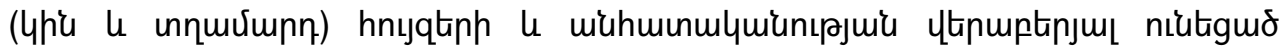

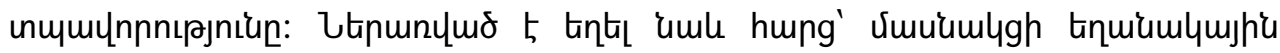

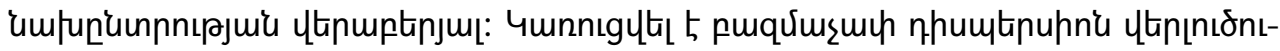

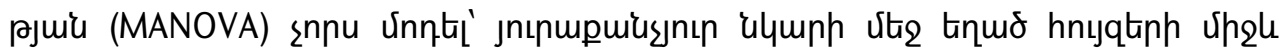

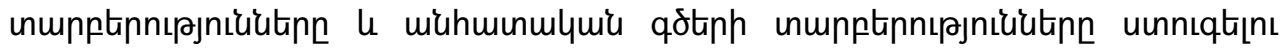

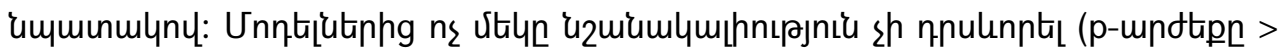

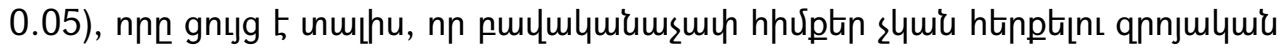

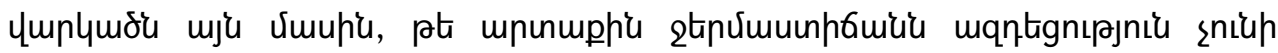

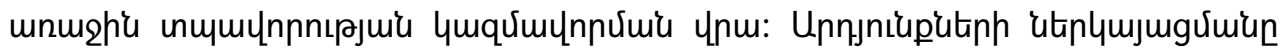

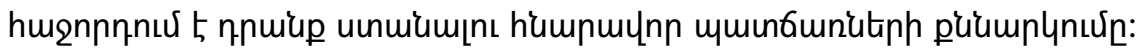

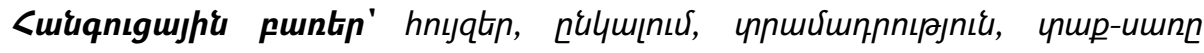

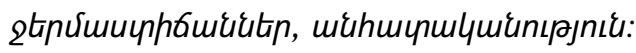

